\title{
Selecting indicators for the Smart City Pilot in Knowledge Oasis Muscat (KOM), Sultanate of Oman
}

\author{
Shaima Al Mahrooqi \\ Information Technology Authority (ITA) \\ Oman \\ shaima.almahrooqi@ita.gov.om
}

\author{
Judy Backhouse \\ United Nations University (UNU-EGOV) \\ Portugal \\ backhouse@unu.edu
}

\begin{abstract}
This paper presents a process for selecting the most appropriate standard indicators for the Smart City Pilot being implemented in Knowledge Oasis Muscat (KOM) in the Sultanate of Oman, by the Information Technology Authority (ITA) in cooperation with the Public Establishment for Industrial Estate (Madayn). The indicators were selected by reviewing and analysing regional and international standards developed to measure smart city performance and progress. Seven indicator standards, with a total of 410 indicators were analysed. The selection of the indicators considered critical aspects of the pilot project. These included the strategic objective of implementing the pilot, the phase of the pilot development, the purpose of the assessment, the urban focus and the city sectors being addressed by the pilot. The results provide a suitable set of indicators from these standards, aligned with the assessment objectives and the smart city pilot project.
\end{abstract}

\section{CCS CONCEPTS}

- Applied computing $\rightarrow$ Computers in other domains $\rightarrow$ Computing in government $\rightarrow$ E-government

\section{KEYWORDS}

smart city indicators; smart city measures; indicator sets; smart city pilot

\section{ACM Reference format:}

Shaima Al Mahrooqi, Judy Backhouse. 2020. Selecting indicators for the Smart City Pilot in Knowledge Oasis Muscat (KOM), Sultanate of Oman. In Proceedings of the $13^{\text {th }}$ International Conference on Theory and Practice of Electronic Governance (ICEGOV 2020), 23-25 September 2020, Athens, Greece. 4 pages. https://doi.org/10.1145/3428502.3428622

\section{INTRODUCTION}

Permission to make digital or hard copies of all or part of this work for personal or classroom use is granted without fee provided that copies are not made or distributed for profit or commercial advantage and that copies bear this notice and the full citation on the first page. Copyrights for components of this work owned by others than the author(s) must be honored. Abstracting with credit is permitted. To copy otherwise, or republish, to post on servers or to redistribute to lists, requires prior specific permission and/or a fee. Request permissions from Permissions@acm.org.

ICEGOV'20, September 23-25, 2020, Athens, Greece

(c) 2020 Copyright is held by the owner/author(s). Publication rights licensed to ACM. ACM ISBN 978-1-4503-7674-7/20/09...\$15.00

https://doi.org/10.1145/3428502.3428622
Economic challenges and the drop in global oil prices have forced Oman to change its strategy away from depending on oil revenue, towards diversification strategies and to encourage growth [1]. There is an infrastructure investment plan for the development of Oman's logistics, transportation and information, and communication technology [2]. Oman vision 2040 along with eOman 2030 strategy, are looking to improve the quality of life, facilitated by technology and smart infrastructure, enabling people to enjoy social welfare and building a diversified, globally competitive economy. According to the Global Information Technology Report, Oman ranked 52 in network readiness in 2016 reflecting a good level of ICT development. The country is ready to leverage the opportunities from adopting technologies and moving toward smart and sustainable infrastructure [3].

Smart City Pilot in Knowledge Oasis Muscat (KOM) is one of Oman's national projects implemented by the Information Technology Authority (ITA) in cooperation with the Public Establishment for Industrial Estate (Madayn). The pilot is implementing smart solutions for parking, traffic management, lighting, safety and security, waste management and environmental monitoring. These will showcase how fourth industrial revolution technologies enable efficiency and a higher quality of life. The pilot will also be used to develop national strategies for smart cities and smart infrastructure including a reference model, policies, regulations, standards and measurement tools. These will then guide and direct public and private entities to participate in implementing future smart city projects.

This paper reports on one of these objectives, developing measurement tools, by selecting a set of suitable indicators to form a framework to assess and monitor the progress and performance of the pilot project. The paper makes use of the taxonomy developed by Huovila et al. [5] which classified indicators according to their urban focus, application domain and indicator type. 


\section{BACKGROUND}

There are many indicators available for measuring the smartness and sustainability of cities. These come from sources including international bodies, private and public entities, and academic research [4]. This work focused on indicator standards from regional and international organizations, after looking at the intended purpose of the tools, what they measure, their transparency, and who can use them. International indicators are preferred because they allow for comparability over time and between cities, and they tend to be transparent [5].

\subsection{Indicator Standards}

This analysis considered international indicator standards published recently by regional and international organizations and applicable as measures of a smart and sustainable city. Seven standards from four different sources (ISO, ITU, ETSI, and UNHabitat) with a total of 410 indicators, were examined (Table 1).

Table 1: Indicator standards examined

\begin{tabular}{|c|c|c|}
\hline NAME & DESCRIPTION & $\begin{array}{l}\text { NUMBER OF } \\
\text { INDICATORS }\end{array}$ \\
\hline $\begin{array}{l}\text { ISO 37122:2019 } \\
{[6]}\end{array}$ & $\begin{array}{l}\text { Sustainable development in } \\
\text { communities-indicators for Smart cities }\end{array}$ & 82 \\
\hline $\begin{array}{c}\text { ISO } 37120: 2018 \\
{[7]}\end{array}$ & $\begin{array}{c}\text { ISO37120:2018 sustainable development } \\
\text { of communities-indicators for city } \\
\text { services and quality of life }\end{array}$ & 104 \\
\hline $\begin{array}{l}\text { ETSI TS } 103 \\
463: 2017 a[8]\end{array}$ & $\begin{array}{l}\text { Key performance indicators for } \\
\text { sustainable digital multi service cites }\end{array}$ & 76 \\
\hline $\begin{array}{l}\text { ITU 4901:2016 } \\
{[9]}\end{array}$ & $\begin{array}{l}\text { Key performance indicators related to } \\
\text { the use of information and } \\
\text { communication technology in Smart } \\
\text { sustainable cities }\end{array}$ & 48 \\
\hline $\begin{array}{l}\text { ITU } 4902 \\
(\text { ITU,2016) [10] }\end{array}$ & $\begin{array}{l}\text { Key performance indicators related to } \\
\text { the sustainability impacts of } \\
\text { information and communication } \\
\text { technology in Smart sustainable } \\
\text { cities(ITU,2016c) }\end{array}$ & 30 \\
\hline $\begin{array}{l}\text { ITU 4903:2016 } \\
\text { [11] }\end{array}$ & $\begin{array}{l}\text { Key performance indicators for Smart } \\
\text { sustainable cities to assess the } \\
\text { achievement of sustainable } \\
\text { development goals }\end{array}$ & 52 \\
\hline $\begin{array}{l}\text { UN SDG } 11+ \\
{[12]}\end{array}$ & $\begin{array}{c}\text { Monitoring framework (UN-Habitat } \\
\text { etal.,2016) }\end{array}$ & 18 \\
\hline \multicolumn{2}{|c|}{ TOTAL number of indicators } & 410 \\
\hline
\end{tabular}

The ISO 37120 standard, published in July 2018, focuses on the performance of city services and quality of life. The recently published ISO 37122 standard focuses more on smart enabling technologies, and was released in May 2019 as a complement to ISO 37120 . Huovila et al. [5] argue that ISO 37122 should be used in combination with the ISO 37120 indicators for sustainability to provide a comprehensive set of city indicators.

The three ITU standards for smart sustainable cities have minor differences in emphasis. ITU 4903 concentrates on assessing the sustainable development goals (SDGs), while ITU 4902 focuses on sustainability impacts and ITU 4901 on the usage of ICT. However, there were no definitions available for the ITU indicators and details on how to measure and collect data were only provided for ITU 4903, in the KPI manual prepared by United 4 Smart Sustainable Cities (U4SSC) [5].

ETSI indicators were developed by the European Union based on an analysis of the requirements of 20 cities. This standard, using an existing framework, was tested for feasibility in about 50 cities. The standard was published in January 2017 with a focus on the sustainable digital multi-service city indicators [5].

Finally, the SDGs are an international framework established in September 2015 with 17 goals, 169 targets, and 230 indicators to guide country plans, priorities, and investment to reduce poverty and promote development. One of the 17 goals is goal 11: Sustainable Cities and Communities, which is an effective fit for this study. The goal includes eleven objectives to make cities inclusive, safe, resilient, and sustainable [12].

\subsection{Acceptance Criteria}

Having clear acceptance criteria is important for the selection of indicators. The criteria for selecting the indicators were drafted from a web search, looking to other experiences in this field. The following criteria meet the pilot's strategic goals and the intentions of the assessment.

Table 2: Acceptance criteria for indicators

\begin{tabular}{|c|c|}
\hline CRITERION & DESCRIPTION \\
\hline Relevance & $\begin{array}{l}\text { Each indicator should have a strong link to the } \\
\text { subthemes of the framework and should have a } \\
\text { significant importance for the evaluation process. }\end{array}$ \\
\hline Reliability & $\begin{array}{l}\text { - The definitions of the indicators should be clear } \\
\text { The calculation methods behinds the indicators } \\
\text { should be specified. } \\
\text { Guidance on how the indicators are to be applied }\end{array}$ \\
\hline Data availability & $\begin{array}{l}\text { Data for the indicators should be easily available, or easy } \\
\text { to collect }\end{array}$ \\
\hline Measurability & $\begin{array}{l}\text { The indicators should be capable of being measured } \\
\text { (quantitative, qualitative and descriptive) }\end{array}$ \\
\hline Alignment & $\begin{array}{l}\text { Alignment of the indicators with the rationale behind } \\
\text { implementing the smart city pilot and the purpose of the } \\
\text { assessment }\end{array}$ \\
\hline Comparability & $\begin{array}{l}\text { The set of indicators should be defined in a way that data } \\
\text { can be compared between different phases of urban } \\
\text { development. }\end{array}$ \\
\hline Familiarity & The indicators should be easy to understand by the users \\
\hline Non- redundancy & $\begin{array}{l}\text { Indicators within a framework should not measure the } \\
\text { same aspect of a subtheme. }\end{array}$ \\
\hline
\end{tabular}

\subsection{Classification for Indicator Analysis}

Huovila et al. [5] developed a taxonomy for smart city indicators that classifies them according to the urban focus, application domain, and indicator type. Consequently, this work used the taxonomy to identify suitable indicators for the Smart City Pilot.

\subsubsection{Urban Focus}

Urban focus refers to the extent to which an indicator measures smartness or sustainability or both [5]. Both sustainability and smartness are critical for the pilot. Therefore, indicators were selected that addressed both of these goals. 
Selecting indicators for the Smart City Pilot in Knowledge Oasis Muscat (KOM), Sultanate of Oman

\subsubsection{Application Domain}

The Smart City Pilot covers three application domains: (1) environment (air quality, smart energy management, smart water management, and smart waste management), (2) quality of life dimension (public transportation, and safety and security), and (3) infrastructure (urban mobility). Hence, indicators were selected that were related to these application domains.

\subsubsection{Indicator Type}

Finally, the indicators were classified in terms of what they were measuring (input, process, output, outcome, and impact). As the pilot is in the implementation stage, data is more easily available for input, process and output indicators and less likely to be available for outcome and impact indicators. A balance of the five types of indicators was considered desirable.

\section{METHODS}

First, the seven indicator standards were identified. The international indicator standards were considered applicable for this pilot due to their wide use and comparability. They were anticipated to be adaptable to use in different cities, globally, regardless of scale, structure, and stage of implementation.

Second, the criteria for selecting the most appropriate indicators were defined (Table 2). The criteria were chosen after an online search and examining other experiences in selecting acceptance criteria, considering the needs of ITA and the Smart City Pilot. Eight criteria were identified that are considered to be important for the evaluation. Each indicator to be selected should meet all of these acceptance criteria.

Third, every indicator was analysed for the three main aspects of the pilot, (1) the urban focus, (2) the application domain and (3) the indicator type. The indicator taxonomy of Huovila et al. [5] was adopted and indicators with an urban focus and application domain not aligned with the pilot were excluded.

Finally, the remaining indicators were scored by assigning one point as a score for each acceptance criterion, and a score of eight was needed for an indicator to be accepted. Details of analysis and scoring, as well as the full list of indicators selected, can be found in [14].

\section{RESULTS}

There were four main findings:

Out of the seven international standards and 410 indicators, a total of 31 indicators were considered suitable for the pilot. The primary sources of these indicators are ISO 37122, ISO 37120, ETSI, and ITU 4903. The indicators from both ITU 4902 \& ITU 4901 were excluded as they did not meet the acceptance criteria for reliability, comparability, and familiarity. For both of these standards, there is only a concise description of the definition of the indicators, and no clear guidance on the calculation methodology and how the indicator should be applied. In addition, the UN SDG 11+ indicators were not suitable as the urban focus was on sustainability only, and not on smartness.
ICEGOV 2020, 23-25 September 2020, Athens, Greece

Table 3: Indicators and standards identified for pilot

\begin{tabular}{|l|l|c|c|}
\hline \multicolumn{1}{|c|}{ NAME } & \multicolumn{1}{|c|}{ DIMENSIONS } & $\begin{array}{c}\text { NUMBER OF } \\
\text { INDICATORS }\end{array}$ & $\begin{array}{c}\text { \% OF } \\
\text { INDICATORS }\end{array}$ \\
\hline ISO 37122 & $\begin{array}{l}\text { Environment, quality of } \\
\text { life, and urban mobility }\end{array}$ & 17 & $55 \%$ \\
\hline ITU 4903 & $\begin{array}{l}\text { Environment, quality of } \\
\text { life, and urban mobility }\end{array}$ & 8 & $26 \%$ \\
\hline ETSI & $\begin{array}{l}\text { Quality of life \& urban } \\
\text { mobility }\end{array}$ & 4 & $13 \%$ \\
\hline ISO 37120 & Quality of life & 2 & $6 \%$ \\
\hline \multicolumn{2}{|r|}{ TOTAL indicators } & $\mathbf{3 1}$ & $\mathbf{1 0 0 \%}$ \\
\hline
\end{tabular}

As shown in Table 3, ISO 37122 and ITU 4903 standards were more appropriate for the pilot than the other indicator standards. Both of these cover all the application domains of the pilot. Out of 31 indicators identified, 17 are from ISO 37122 standard with 11 for the environment dimension, 3 for quality of life and 2 for infrastructure. ITU 4903 provided 8 indicators relevant to the pilot. This standard had indicators for all three of the relevant application domains. Two indicators were identified for environment, 4 for quality of life, and 2 for infrastructure.

Table 4: Selected indicators by dimension

\begin{tabular}{|l|c|c|}
\hline \multicolumn{1}{|c|}{ APPLICATION DOMAIN } & $\begin{array}{c}\text { NUMBER OF } \\
\text { INDICATORS }\end{array}$ & $\begin{array}{c}\text { \% OF } \\
\text { INDICATORS }\end{array}$ \\
\hline Environment & 14 & $45 \%$ \\
\hline Quality of life & 11 & $36 \%$ \\
\hline Infrastructure & 6 & $19 \%$ \\
\hline
\end{tabular}

Most of the indicators identified (45\%) cover the environment dimension, with fewer (36\%) for quality of life, and only $19 \%$ for urban mobility. This result is satisfying as the pilot project is focusing more on the environment.

The result for the indicator type is less satisfying. Fifty-two percent $(52 \%)$ of the indicators are outcome indicators and $36 \%$ are output indicators. Only $6 \%$ of the selected indicators are impact and process indicators and there were no input indicators identified. Input and process indicators are valuable for projects that are starting out and cities new to smart city development [5], so this result does not fulfill the needs of the pilot project. None of the indicator sets have input indicator and there are few process and impact indicators. There is instead a focus on measuring output, outcome and impact indicators because the standards have been developed with more developed countries in mind.

\section{RECOMMENDATIONS}

The process described in this report can be replicated by cities wanting to identify indicators for their projects. Cities need to draw on the taxonomy of Huovila et al. [5] to identify the relevant indicators for their needs.

International standards bodies will serve the needs of developing countries and cities starting out on smart, sustainable projects better if they include input and process indicators in their indicator standards and present a better balance of indicator types. 
If they continue to present only output, outcome and impact indicators they risk having these cities turn to other standards and produce less comparable information.

In the meanwhile, cities in this position should identify their own additional indicators. Input indicators measure the quality, quantity, or timeliness of resources needed to implement a project. Resources might be policies, people, materials or money [13]. Suggested input indicators for this project might be:

- Financial support allocated to the pilot

- Staff allocated to the pilot

- Existence of strategies, rules and regulations

Process indicators measure the activities that have taken place and might include meetings, training courses, distribution of smart meters, etc. [13]. Suggested process indicators for this project might be:

- Evidence of a consistent planning approval process

- Number of smart electricity/ water meters distributed

- Number of air quality monitoring sensors installed

Input and process indicators need to be selected that meet all the other criteria applied in this process.

\section{CONCLUSION}

This report developed a set of indicators suitable for the Smart City Pilot project being implemented in Knowledge Oasis Muscat (KOM) and explained the process of how the indicators were chosen. Indicators will help decision-makers to set future targets, to improve on the pilot project and will provide a basis for decisions on future projects.

This study set up eight selection criteria for the indicators and identified 31 indicators that are aligned with the urban focus and application domains of the pilot project. The final selection lacked input and process indicators, which are important for new projects, so the identified set needs to be supplemented with additional indicators to understand how resources are being used and what activities are taking place.

One remaining concern is some uncertainty about data availability. This needs to be assessed with the project team. Therefore, the study is still on-going, and improvements to the indicators list are expected to develop a good assessment framework.

This study provides guidance for other entities to develop assessment indicators for their own smart city projects and initiatives. The approach described can be followed by others to arrive at a set of suitable indicators for smart city projects.

\section{ACKNOWLEDGEMENT}

This paper is a result of the project "SmartEGOV: Harnessing EGOV for Smart Governance (Foundations, methods, Tools) / NORTE-01-0145-FEDER-000037", supported by Norte Portugal
Regional Operational Programme (NORTE 2020), under the PORTUGAL 2020 Partnership Agreement, through the European Regional Development Fund (EFDR).

\section{REFERENCES}

[1] The National Program for Bracing the Economic Diversity (TANFEEDH). Retrieved 25 August 2019 from https://www.scp.gov.om/en/Page.aspx?I=37

[2] Oman Vision. The Preliminary Oman 2040 Vision Document. Retrieved 25 August 2019 from https://www.2040.om/en/vision-realizationindicators/

[3] S. Baller, S. Dutta, \& B. Lanvin. 2016. The Global Information Technology Report 2016. World Economic Forum. Retrieved 25 August 2019 from http://reports.weforum.org/global-information-technologyreport-2016/

[4] J. Backhouse. 2019. A Review of Measures to Evaluate Smart Sustainable Cities. Proceedings of the First EAI International Conference for Sustainable Smart Cities (SmartGov 2019), 4-6 December, 2019. Braga, Portugal.

[5] A. Huovila, P. Bosc, \& M. Airaksinen. 2019. Comparative analysis of standardized indicators for Smart sustainable cities: What indicators and standards to use and when?. Cities, 89, 141-153. DOI: 10.1016/j.cities.2019.01.029

[6] International Organization for Standardization. 2019. ISO 37122:2019 Sustainable cities and communities - Indicators for smart cities. Retrieved 22 August 2019 from https://www.iso.org/standard/69050.html

[7] International Organization for Standardization. 2018. ISO 37120:2018 Sustainable cities and communities - Indicators for smart cities. Retrieved 22 August 2019 from https://www.iso.org/standard/69050.html

[8] European Telecommunications Standard Institute. 2017. ETSI TS 103 463:2017a Key performance indicators for sustainable digital multi service cities. Retrieved 22 August 2019 from https://www.etsi.org/standards\#search=ETSI\%20TS\%20103\%20463\%3A2 $\underline{017 \mathrm{a}}$

[9] International Telecommunication Union. 2016. Recommendation ITUTY.4901/1.1601 Key performance indicators related to the use of the information and communication technology in smart sustainable cities. Retrieved 22 August 2019 from https://www.itu.int/rec/T-REC-L.1601201606-I/en

[10] International Telecommunication Union. 2016. Recommendation ITUTY.4902/1.1602 Key performance indicators related to the sustainability impacts of information and communication technology in smart sustainable cities. Retrieved 22 August 2019 from https://www.itu.int/rec/T-REC-L.1602-201606-I

[11] International Telecommunication Union. 2016. Recommendation ITUTY.4903/1.1603 Key performance indicators for smart sustainable cities to assess the achievement of Sustainable Development Goals. Retrieved 22 August 2019 from https://www.itu.int/rec/T-REC-Y.4903/en

[12] Goal 11: Sustainable Development Knowledge Platform. 2019. Retrieved 30 August 2019 from https://sustainabledevelopment.un.org/sdg11

[13] P. Bosch, S. Jongeneel, V. Rovers, H-M. Neumann, M. Airaksinen \& A. Huovila. 2017. CITYkeys indicators for smart city projects and smart cities. Retrieved 25 September 2019 from http://nws.eurocities.eu/MediaShell/media/CITYkeysD14Indicatorsfors martcityprojectsandsmartcities.pdf

[14] Al Mahrooqi, S. (2019). Selecting indicators for the Smart City Pilot in Knowledge Oasis Muscat (KOM), Sultanate of Oman. UNU-EGOV. Retrieved from https://egov.unu.edu/ 